\title{
God Versus the Human Genome
}

\author{
Inside the Human Genome: A Case for Non-Intelligent Design, by John C. Avise. \\ Oxford: Oxford University Press, 2010. Pp. xi + 222. H/b \$19.95.
}

\author{
Adam M. Goldstein
}

Published online: 5 October 2010

(C) Springer Science+Business Media, LLC 2010

According to the argument from design, most famously articulated by William Paley in the late nineteenth century, the complexity and apparent purposiveness of organs such as the eye is evidence for the existence of God. Since Paley, scientists have gained considerable knowledge of the molecular mechanisms of many fundamental biological processes and their evolution. Notably, in 2001, scientists reached an important milestone. After years of work, they sequenced the entire human genome. Proponents of the argument from design recognize the importance of molecular biology and, just as the discipline of biology as a whole, have extended their work to the molecular scale. Members of the "intelligent design" movement, represented most prominently by Michael Behe, argue that if molecular evidence is accounted for, the evidence for design is irrefutable. Avise, in Inside the Human Genome, advances compelling arguments against this claim.

Avise proceeds by the strategy known as the method of hypothesis. On the method of hypothesis, a view that better explains phenomena in question is better supported by those phenomena, relative to a view that does not explain them as well. Antagonists in the dispute over the argument from design typically contend over whether design or evolutionary theory better explains organic adaptation, particularly complex adaptations. Richard Dawkins is a central figure in this discussion. Does the view that an expert engineer with divine, or at any rate extraordinary power, explain adaptation better

\footnotetext{
A. M. Goldstein $(\varangle)$

Department of Philosophy, Iona College,

715 North Avenue, New Rochelle,

New York 10801, USA

e-mail: z_californianus@shiftingbalance.org
}

than evolutionary biology? Those arguing for design often claim that complex adaptation could not have arisen by natural forces alone, requiring an intelligent designer. Against this, it is argued that the mechanisms of evolution described by evolutionary biology as we know it today can explain adaptation.

Avise focuses on the poor design, rather than the adaptedness, of the human genome. This changes the context of the argument considerably. Organs such as the eye are so remarkable that many people have trouble accepting that they are a product of nature. In contrast, if the human genome is characterized by inefficiency, susceptibility to error, and apparently useless components which can cause illness, the design hypothesis is at a clear disadvantage. Why would an expert designer build the genome in this way? The claim that design flaws in the human genome were created by historical processes such as natural selection, mutation, and random drift is clearly stronger than the design hypothesis. The argument from design dovetails with the problem of evil: if the deity is benevolent, why do we suffer? Our bodies and as Avise points out, the human genome in particular, have structural weaknesses that no conscientious engineer would permit. Perhaps the creator is not such a good designer after all; or if $\mathrm{He}$ is a good designer, perhaps $\mathrm{He}$ is not so benevolent after all. Here again, Avise approaches the philosophical and theological issues by looking at our failure to adapt, rather than by looking at our success. Although the general strategy of looking at maladaptedness is not new, Avise's contribution is novel because it concerns the human genome. The excellence of Avise's explanation of the religious and philosophical issues and the strength of his argument also distinguish the book from others on the topic. 
The evidence is striking and Avise's delivery of it so effective that, while reading Inside the Human Genome, it is difficult to escape the feeling created by the best stories of Edgar Allen Poe: a sense of decrepitude, as though every cell division poses a mortal danger. Avise identifies three central aspects of the genome in which its structural components and basic processes are clearly lacking. Chapter 2, "Fallible Design," concerns the problems that can arise in coding sequences of DNA. Our genes code for proteins; a section of the DNA is transcribed to RNA, beginning the process by which a gene is expressed. Coding sequences are rife with error. Avise describes the $M M B I D$, The Metabolic and Molecular Bases of Inherited Disease, a reference work of 255 chapters, each of which is about a heritable disease caused by mutation in a coding sequence. The book is 6,000 pages long, in four volumes, and lists more than 500 diseases.

Chapter 3, "Baroque Design: Gratuitous Genomic Complexity," is about ways in which a cell carries out metabolic functions in error-prone, roundabout pathways. For instance, as it happens, coding sequences of DNA are not continuous: rather, a coding sequence has two components, introns and exons. Introns are "intra-gene" spacers. During the process of transcription, introns are removed from the coding sequence, contributing nothing to the resulting protein product. The mechanisms required to remove the introns and join the exons can fail at many points in the process, providing ample opportunity for errors that cause disease. Other structures and processes prone to error include mitochondrial DNA and genes "imprinted" by the mother or the father, the function of the gene depending upon which parent it originated with.

Chapter 4, "Wasteful Design: Repetitive DNA Elements," addresses the issue of what appears to be useless DNA scattered broadly across the genome. "To the best of current knowledge, many if not most of these repetitive elements contribute not one iota to a person's well-being. They are well-documented, however, to contribute to many health disorders" (p. 107). This class of genetic defects includes duplicate genes, pseudogenes, microsattelites, and mobile elements. Duplicate genes can cause errors in the crossing-over processes. As the chromosomes trade genetic material during the process of meiosis, a duplicate gene can take the place of the original gene, causing the chromosome to break at the wrong place, destroying the meaning of the DNA code at that point. Mobile elements are perhaps the most interesting repetitive element because they operate by the cold logic of natural selection from within our system of inheritance. Mobile elements will multiply themselves, harming the individual carrying them. The central restraint on how many copies they can produce is set by natural selection. Whatever the amount of damage each element does to its bearer's fitness can be compensated for by increasing the number of elements. Suppose that a human population is host to these mobile elements, which reduce each individual's viability by one percent for each mobile element. The elements need only increase their representation by more than one percent to beat the odds of making it to the next generation.

Avise concludes the book with a chapter detailing what he believes follows from his work in earlier chapters. He consolidates his central conclusion by addressing the claims of ID theorists directly. Historical processes, not intentional action, better explain our genome, the many errors in which make no sense on the assumption that a benevolent deity with expert engineering abilities is responsible. The burden is shifted to the proponent of intelligent design to make sense of the many heritable health problems and other problems in gene expression that lead to human disease. He offers some thoughtful reflections on the relationship between science and religion, suggesting that evolutionary biology and mainstream religion are finding more common ground than differences with one another, while at the same time, creationism and intelligent design are moving further away from both.

Inside the Human Genome is strongly recommended. It is eminently readable. Avise is just as much at home writing about the philosophical and theological issues as he is about the scientific, which he handles knowledgeably and gracefully. The book would make an excellent companion to a college level course in evolutionary biology, or as a main text in a philosophy or a religious studies course; professionals in those disciplines will also find it thought-provoking. The book is an excellent overview of human genetics because each genetic infirmity addressed by Avise occurs in fundamental structures and processes of inheritance and gene expression. The main text is largely free of complex technical detail, which is explained in endnotes and a glossary. An extensive list of further reading is appended to the book. 